\title{
LA Oportunidad, PRocedencia E IMPORTANCIA DE UNA NuEVA LEY ORgÁNICA DE LA CONTRALORÍA GENERAL DE LA REPÚBLICA
}

\section{HUMBERTO AVILÉS BERMÚDEZ}

Profesor Adjunto de Derecho Universidad Centroamericana

\footnotetext{
Conceptualmente deben considerarse una serie de características a ser

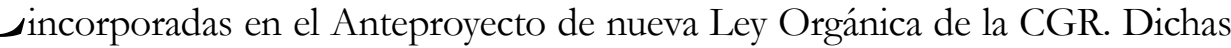
características fueron identificadas y ordenadas metodológicamente durante el desarrollo del proceso de redacción del Borrador para un Anteproyecto de nueva LOCGR, producto de la Consultoría que, con financiamiento de la Cooperación internacional (GTZ de Alemania y AECI de España), se realizó a tales efectos durante el primer semestre del año 2002. No debe omitirse que antes de ser aprobado el mencionado borrador por el Consejo Superior de la Entidad Fiscalizadora Superior, fue ampliamente discutido y revisado por el Comité Jurídico Institucional de la Contraloría incorporando una serie de aportes técnicos, tanto jurídicos como de Auditoria. Finalmente, dicho Anteproyecto de Nueva Ley Orgánica se remitió de manera oficial por el Consejo Superior de la Contraloría a la Junta Directiva de la Asamblea Nacional para su presentación como iniciativa de Ley, en Febrero de 2004 conforme a lo resuelto en Sesión Ordinaria No. 335 del mismo Consejo.

Debemos destacar que la propuesta conceptual a la que nos estamos refiriendo, parte de una visión sistémica tanto del Control como de la Auditoría, misma que desarrollamos en catorce principios metodológicamente organizados, a saber:

1. Concepción sistémica.

2. Naturaleza técnico administrativa.

3. Sistema adjetivo.

4. Orientación positiva.

5. Universalidad de sujetos.

6. Globalidad de objeto.

7. Unidad de dirección.

8. Independencia.

9. Acceso irrestricto.

10. Corresponsabilidad.

11. Centralización normativa.

12. Descentralización operativa.

13. Coordinación y cooperación.

14. Profesionalización.
} 
Una breve descripción de cada una de las características reseñadas, nos permite hacernos una idea más clara y completa de la importancia que reviste para la Contraloría General de la República, y por ende, para la lucha contra la corrupción y la construcción de una gestión administrativa pública transparente, un nuevo marco legal en materia de control que defina las reglas del juego al respecto, actualizándolas en el plano interno y externo, o sea, homologando nuestra legislación con las más avanzadas al menos en el ámbito regional latinoamericano.

\section{Concepción sistémica}

Aquí cabe referirnos a los Ejecutores: Subsistema de Control Interno y Subsistema de Control Externo, y al Objeto: Sistemas Administrativos, Sistemas Operativos y Sistemas de Información.

\section{Naturaleza Técnico Administrativa}

Parte del Control administrativo como base de una pirámide cuyo primer peldaño es ocupado por el que ejercen cada entidad y organismo públicos, el segundo peldaño o nivel es el ocupado por otros organismos de Control Externo que deben informar a la CGR, y en la cúspide o nivel máximo está la Contraloría General, en tanto máxima autoridad de Control constitucionalmente prevista. De manera que el control administrativo vendría a ser como el control por excelencia en materia de servicio público.

En un plano complementario y/ o colateral de la pirámide del Control, tenemos al Control Político ejercido por la Asamblea Nacional en cada legislatura, y al Control Judicial ejercido por los Tribunales y juzgados según competencias, sin perder de vista al Control Social ejercido por la sociedad en su conjunto sobre los tres controles previamente citados.

\section{Sistema Adjetivo}

Con esto se quiere destacar que el control es un medio, no es un fin en sí mismo, recordemos que coadyuva a la obtención de fines institucionales.

\section{Orientación Positiva}

Significa que al ejercer control se proponen mejoras a la gestión del sujeto(s) controlado, lógicamente esta orientación logra su objetivo cuando las recomendaciones hechas se cumplen. 


\section{Universalidad de sujetos}

Significa que toda entidad u organismo y todo servidor público, sin excepciones, deben someterse al escrutinio del control y a sus consecuencias,

\section{Globalidad del objeto}

Este principio aclara que el objeto del control es la gestión pública integral: incluye por tanto, Sistemas Administrativos, Operativos y de Información.

\section{Unidad de Dirección}

Tiene que haber un solo ente rector, jerárquicamente superior, respetable y respetado, justo y equitativo que controle: El uso que los administradores hacen de las facultades y recursos puestos a su disposición por la sociedad; y los resultados obtenidos en la satisfacción de necesidades públicas.

\section{Independencia}

En tres niveles: -Contraloría debe tener independencia funcional, así como autonomía administrativa y presupuestaria.

- Auditoría interna: independencia funcional y dependencia administrativa.

- Auditor: Debe tener independencia plena para poder ser objetivo y no influenciado.

\section{Acceso Irrestricto}

La Contraloría en el ejercicio de su trabajo debe tenerlo irrestrictamente a: Entidades, funcionarios y empleados, a terceros relacionados, a información y documentación y a operaciones en sí mismas, cuando corresponda.

\section{Corresponsabilidad}

En el ejercicio del control debe haber corresponsabilidad a nivel de Control interno:- por cada entidad u organismo. -Previo y concurrente, el establecido en los procesos. -Posterior, por unidades de auditoría interna.

Control Externo: Contraloría y otros organismos (Superintendencias de Bancos, Pensiones, etc.). 


\section{Centralización Normativa}

La Contraloría emite:-Normas Técnicas de Control Interno.- Políticas de auditoria gubernamental.- Normas técnicas de auditoria gubernamental.-Otras regulaciones administrativas para el funcionamiento del sistema.

\section{Descentralización Operativa}

El Control Interno es una responsabilidad gerencial de cada entidad pública.

\section{Coordinación y Cooperación}

A lo interno: Entre las unidades administrativas. A lo externo:-Con las unidades de auditoria interna.

- Con entidades ejecutoras.

- Con otros organismos de Control.

- Con el Ministerio Público.

- Con la Asamblea Legislativa.

\section{Profesionalización}

La función de Control debe estar sujeta a normas profesionales y ejercida por auditores con competencia profesional, esto es: Contadores Públicos Autorizados y: Otros profesionales, todos titulados y autorizados para ejercer en el país. Entendiéndose que la Auditoria constituye la herramienta metodológica profesional del Control.

Ese es el contenido imprescindible para desarrollar un Borrador de Anteproyecto de Nueva Ley Orgánica de la CGR corto, ágil y eficaz, susceptible por su neutralidad técnica de incorporar los cambios que sean derivados de la evolución social, política y económica posteriores. Para concluir, nos permitimos insertar un cuadro que de manera general compara la Ley Orgánica vigente con el Anteproyecto: 
DIFERENCIAS GENERALES

ANTEPROYECTO LEY ORGANICA DE LA

CONTRALORIA GENERAL DE LA REPUBLICA

Y LEY ORGANICA ACTUAL

\begin{tabular}{|c|l|l|l|}
\hline No & & \multicolumn{1}{|c|}{ ANTEPROYECTO } & \multicolumn{1}{|c|}{ ACTUAL } \\
\hline 1 & Extensión & 86 Arts. & 186 Arts. \\
\hline 2 & Carácter & Concisa & Detallada \\
\hline 3 & Relaciones & Otros sistemas & No \\
\hline 4 & Cooperación & Otros Órganos de Control & No \\
\hline 5 & Precisión & Mayor & Menor \\
\hline 6 & Aplicación de principios & Mayor & Menor \\
\hline
\end{tabular}

DIFERENCIAS EN CONTROL Y AUDITORIA

\begin{tabular}{|c|l|l|c|}
\hline No. & & \multicolumn{1}{|c|}{ ANTEPROYECTO } & ACTUAL \\
\hline $\mathbf{1}$ & Sujeto & Sin excepción & Con excepción \\
\hline $\mathbf{2}$ & Objeto & Gestión total & $\begin{array}{l}\text { Recursos } \\
\text { públicos }\end{array}$ \\
\hline $\mathbf{3}$ & Enfasis & Auditoria de gestión & $\begin{array}{l}\text { Ex. Es.- audit. } \\
\text { Financiera }\end{array}$ \\
\hline $\mathbf{4}$ & Contratación de firmas & $\begin{array}{l}\text { Contraloría } \\
\text { Entidades }\end{array}$ & $\begin{array}{c}\text { Si } \\
\text { No }\end{array}$ \\
\hline $\mathbf{5}$ & Sigilos & Menores & Mayores \\
\hline $\mathbf{6}$ & Evidencia & $\begin{array}{l}\text { Sustentable para defensa en } \\
\text { juicio }\end{array}$ & No \\
\hline $\mathbf{7}$ & Normas institucionales & $\begin{array}{l}\text { Para control } \\
\text { Interno }\end{array}$ & No \\
\hline $\mathbf{8}$ & $\begin{array}{l}\text { Deficiencia del control } \\
\text { interno }\end{array}$ & $\begin{array}{l}\text { Origina suspensión de } \\
\text { recursos }\end{array}$ & No \\
\hline
\end{tabular}

DIFERENCIAS ORGANIZACIONALES

\begin{tabular}{|c|l|c|c|}
\hline No. & & ANTEPROYECTO & ACTUAL \\
\hline 1 & Independencia funcional & Sí & No \\
\hline 2 & $\begin{array}{l}\text { EE.FF. CGR } \\
\text { Dictaminados }\end{array}$ & Sí & No \\
\hline 3 & Procuración Judicial & Sí & No \\
\hline
\end{tabular}


